\title{
Correlation and Path Coefficient Analysis for Yield Contributing Parameters in Chrysanthemum (Dendranthema grandiflora Tzvelev)
}

\author{
Beeralingappa $^{1 *}$, P. Hemanth Kumar ${ }^{2}$, Pruthvi P. Hegde ${ }^{1}$ and S.Y. Chandrashekhar ${ }^{1}$ \\ ${ }^{1}$ Department of Floriculture and Landscape Architecture, College of Horticulture, \\ Mudigere-577132, India \\ ${ }^{2}$ University of Agricultural and Horticultural Sciences, Shivamogga -577 204, \\ Karnataka, India \\ *Corresponding author
}

\begin{tabular}{|c|}
\hline \\
\hline $\begin{array}{l}\text { Chrysanthemum, } \\
\text { Correlation, Path } \\
\text { analysis, Genotypic, } \\
\text { Phenotypic and } \\
\text { Flower yield }\end{array}$ \\
\hline Article Info \\
\hline $\begin{array}{l}\text { Accepted: } \\
\text { 20 June } 2019 \\
\text { Available Online: } \\
\text { 10 July } 2019\end{array}$ \\
\hline
\end{tabular}

\section{A B S T R A C T}

Correlation and path analysis were carried out in 16 genotypes of chrysanthemum (Dendranthema grandiflora Tzvelev) for different yield attributing traits. Among twelve different parameters to differentiate the contribution made by each parameter in the final flower yield. The results revealed that the genotypic correlations were higher than the phenotypic correlations for the characters studied, indicating the high heritable nature of the characters. The genotypic correlation of flower yield per plant was showed highly significant and positive correlation with leaf area $(0.885)$, number of leaves per plant (0.714), number of flowers per plant (0.677), duration of flowering (0.640), plant height (0.609), number of primary branches per plant (0.575), stem girth (0.531), flower weight $(0.542)$ and number of secondary branches per plant $(0.441)$. While, non-significantly positive correlation for flower yield per plant was observed with internodal length $(0.186)$ and flower diameter (0.268). Since these associations are in desirable direction and selection of these traits may ultimately improve the yield. Path coefficient result revealed that the number of flowers per plant (1.831), flower weight $(0.701)$, internodal length (0.296), number of secondary branches per plant (0.168), flower diameter $(0.162)$, duration of flowering (0.155) and leaf area (0.088) exhibited maximum positively direct effect on flower yield per plant. Flower yield per plant had negatively direct effect from plant height $(-0.136)$, stem girth $(-0.202)$, number of primary branches per plant $(-0.218)$, number of leaves per plant $(-0.919)$ at the genotypic level. Thus, these characters have maximum contribution towards the flowers yield per plant.

\section{Introduction}

Chrysanthemum (Dendranthema grandiflora Tzvelev) is the leading commercial flower crop grown for cut, loose flowers and pot plants. It is commercially known as 'Queen of East', 'Autumn Queen" and "Guldaudi'. The genus Chrysanthemum belongs to the family 'Asteraceae'. It ranks second in the international cut flower trade. In India, its germplasm has been screened but the information on the performance for the higher yield of the cut flower and yield contributing parameters of Chrysanthemum is meager. 
Many cultivars have been developed from local material collected from different parts of the country. In spite of varietal development there is need to develop genotypes with still better yield, quality and their adaptation under different environment. A variety may perform well only in a particular environment and therefore the genetic potentiality of different genotypes and their interaction with environmental condition are to be established and according to their performance, selection of best growth and flowering traits genotype needs to be done.

A complex association exists among different plant characters and character themselves do not exist in isolation. These characters are often correlated with each other, either due to pleiotrophy or due to genetic linkage (Harland, 1939). For rational approach towards the improvement of yield, selection will be more rewarding when it is based on the components of the yield. The wide range of groups and varieties of this flower made the workers research more complex. Its flower yield is a complex character and is the result of interrelation-ship of various components. Correlation and path coefficient analysis furnishes information regarding the nature and magnitude of various associations and help in the measurement of direct influence of one variable on others. The correlation coefficient indicates the degree of relationship between characters. The type of association between flower yield and yield attributes to judge the direct and indirect influences of flower yield components through path coefficient analysis for selecting suitable genotypes for improving the flower yield. Apart from this, correlation as well as path coefficient is important tools for the selection of desirable traits and to enhance the productivity of chrysanthemum. The main objective of plant breeder is to evolve high yielding varieties of chrysanthemum suitable for cut flower purpose. Therefore, desirable traits for plant breeder to know the extent of relationship between yield and its various components, which will facilitate selection based on component traits (Prasad et al., 2011). Keeping in view the above facts, the present investigation was undertaken with an objective to analyze and determine the traits having greater inter-relationship with flower yield utilizing the correlation and path analysis and to generate such yield components may provide a solid ground for a successful varietal development programme to help breeders in improvement of chrysanthemum.

\section{Materials and Methods}

The experiment was carried out at the College of Horticulture, Hiriyur, Karnataka during July 2015 to January 2016. The treatments in this experimental consisted of sixteen genotypes of chrysanthemum viz., $\mathrm{T}_{1}$ : Pink Cloud, $\mathrm{T}_{2}$ : Star Pink, $\mathrm{T}_{3}$ : White Prolific, $\mathrm{T} 4$ : SharadMala, $\mathrm{T}_{5}$ : Marigold, $\mathrm{T}_{6}$ : Winter Queen, $\mathrm{T}_{7}$ : Autumn Joy, $\mathrm{T}_{8}$ : Basanthi, $\mathrm{T}_{9}$ : Vasanthika, $\mathrm{T}_{10}$ : Chandani, $\mathrm{T}_{11}$ : Lakkundi, $\mathrm{T}_{12}$ : Bellatti, $\mathrm{T}_{13}$ : White Seventige, $\mathrm{T}_{14}$ : Arka Pink Star, $\mathrm{T}_{15}$ : Arka Chandrika and $\mathrm{T}_{16}$ : Arka Chandrakanth. The experiment was laid out in randomized completely Block Design (RCBD) with three replications. The field was divided into three blocks; each block was further divided into sixteen plots i.e. one plot for each treatment. The total number of plots in the experiment was forty eight. Thirty days old rooted cuttings were transplanted on the main field with a spacing of $45 \mathrm{~cm}$ between rows and 45 $\mathrm{cm}$ between the plants. All the recommended cultural practices were followed under irrigated condition. Among twelve different parameters to differentiate the contribution made by each parameter in the final flower yield. The data collected from the genotypes of chrysanthemum on different parameters were subjected to statistical analysis. Correlation coefficients were computed using the method elucidated by Al-Jibouri et al., 
(1958). The direct and indirect effects of component characters on yield were estimated through path analysis technique (Wright, 1921) further it was illustrated by Dewey and $\mathrm{Lu}$ in crested wheat grass seed production (1959).

\section{Results and Discussion}

In the present study flower yield per plant has been taken as dependent variable, whereas, remaining 11 characters were considered as independent variables contributing towards flower yield per plant. The genotypic and phenotypic correlation studies were carried out for 12 various characters (enlisted in Tables 1 and 2) to know the nature of relationship existing between flower yield per plant (g/plant) and its other component characters.

In majority of the characters, genotypic correlation coefficient was found to be higher in magnitude (values) than phenotypic correlation coefficient. This indicates the presence of strong inherent association among various characters but their phenotypic expression was impeded by the influence of environmental factors.

The results revealed that the genotypic correlations were higher than the phenotypic correlations for the characters studied, indicating the high heritable nature of the characters. The genotypic correlation of flower yield per plant showed highly significant and positive correlation with leaf area (0.885), number of leaves per plant (0.714), number of flowers per plant (0.677), duration of flowering (0.640), plant height (0.609), number of primary branches per plant (0.575), stem girth (0.531), flower weight $(0.542)$ and number of secondary branches per plant (0.441). The association of these characters with flower yield per plant is in desirable direction and selection of these may ultimately improve the yield. Therefore, it is suggested to select genotypes performing well for yield attributing characters. These results are in agreement with the earlier reports of Mukesh et al., (2012) and Kameswari et al., (2015) in chrysanthemum.

While, non-significantly positive correlation for flower yield per plant was observed with internodal length (0.186) and flower diameter $(0.268)$. This is because, correlation between two characters is not a simple relationship but is rather the product of interaction of the direct and indirect cause. This result is in line with the findings of Punetha et al., (2012) in chrysanthemum.

With the inclusion of more variables in correlation studies, the indirect association becomes more complex. Two characters may show correlation just because they are correlated with the third one. In such circumstances, path coefficient analysis provides an effective means of finding out direct and indirect effects of association and permits a critical examination of specific forces acting to produce a given correlation and measure the relative importance of each factor. The matrix of direct and indirect effects was presented in the table 3 and 4 .

At the genotypic level, number of flowers per plant (1.831), flower weight (0.701), internodal length (0.296), number of secondary branches per plant (0.168), flower diameter (0.162), duration of flowering $(0.155)$ and leaf area (0.088) exhibited maximum positively direct effect on flower yield per plant. This might be due to the more regional adaptability and growth habit of some of the genotypes resulting in higher proportion of morphological growth as well as reproductive growth leading to increased flower yield. These results are in conformity with the findings of Deka and Paswan (2002), Misra et al., (2013) and Kameswari et al., (2015) in chrysanthemum (Table 5 and 6). 
Table.1 Genotypic correlation coefficient analysis among the different characters on flower yield per plant in various genotypes of chrysanthemum

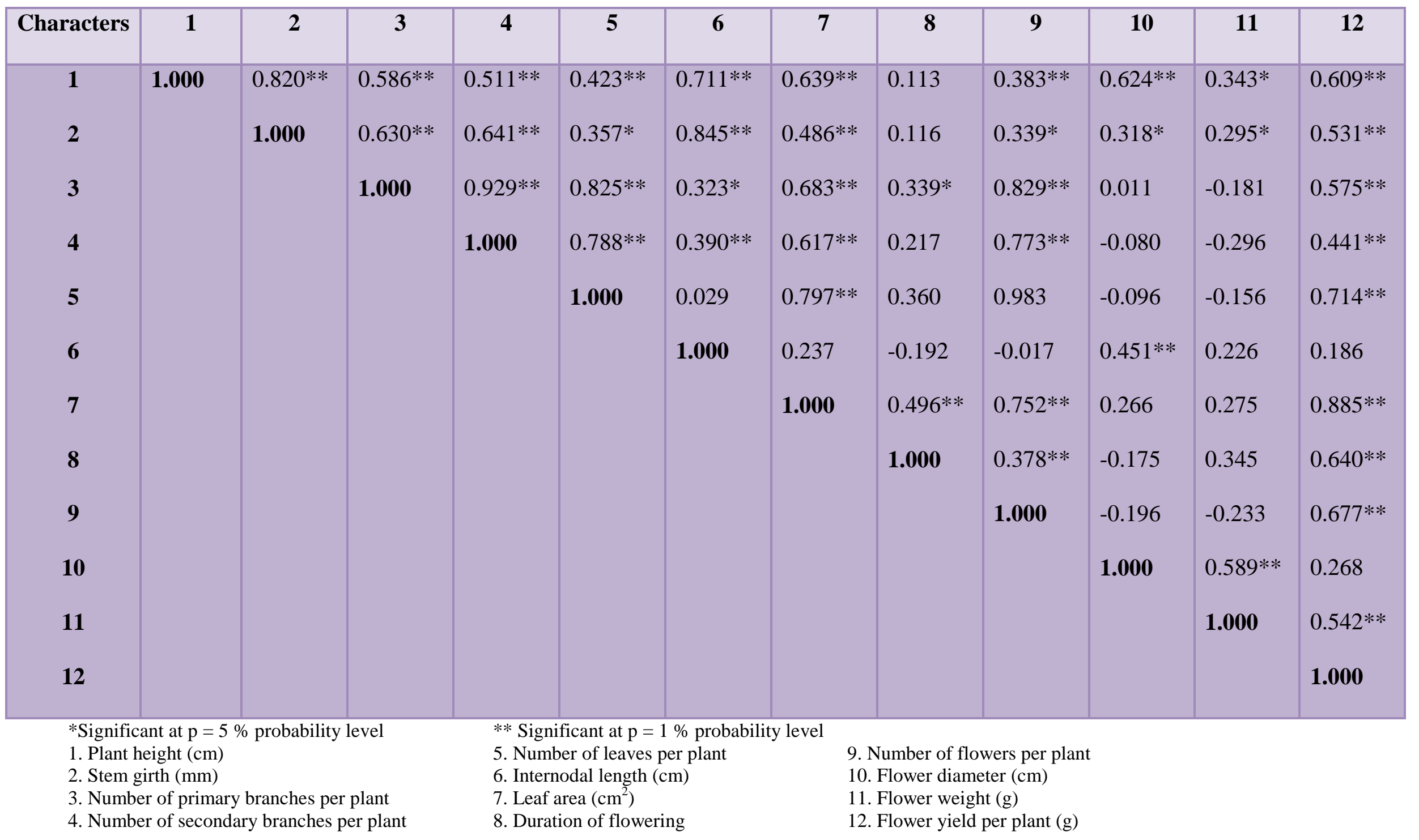


Table.2 Phenotypic correlation coefficient analysis among the different characters on flower yield per plant in various genotypes of chrysanthemum

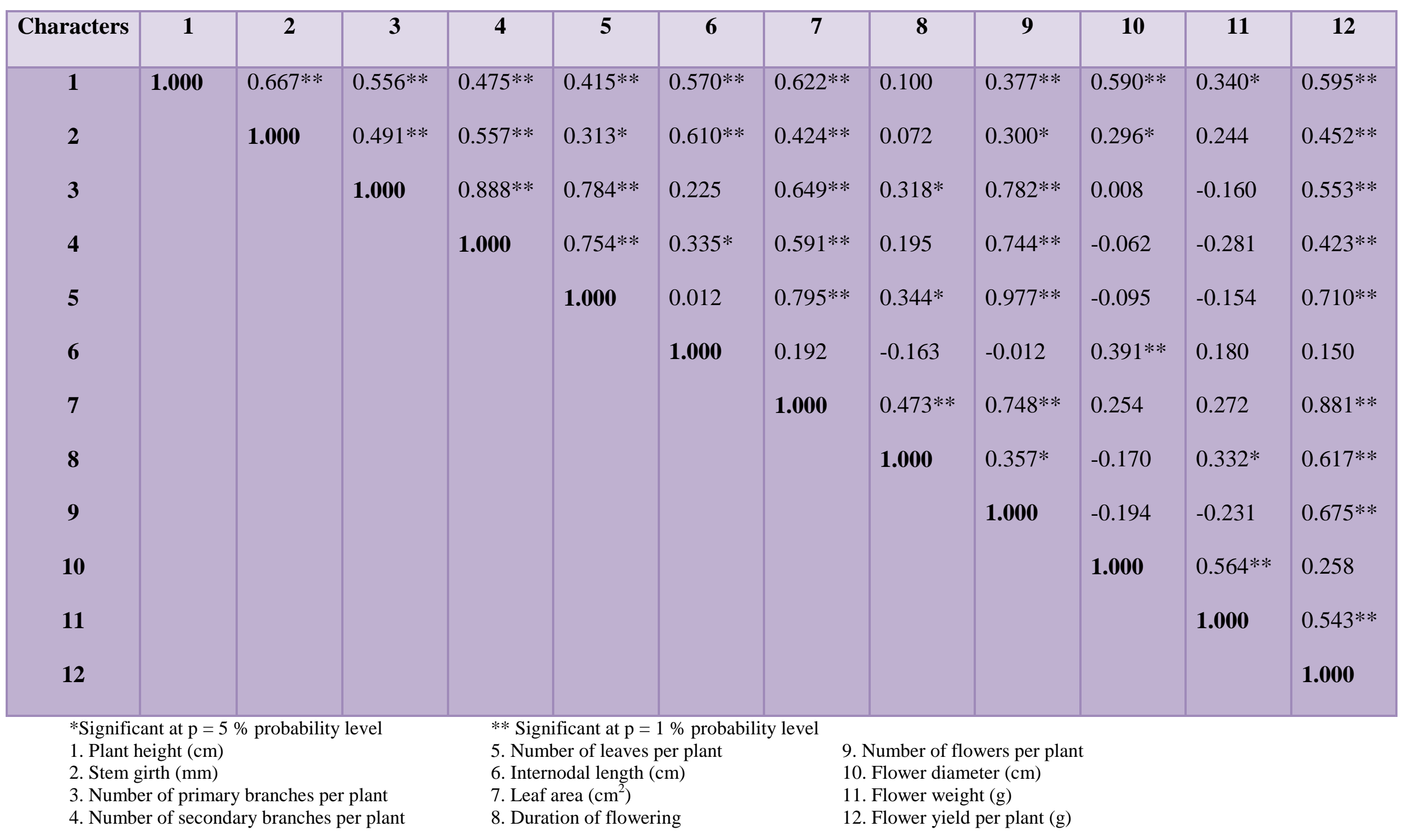


Table.3 Genotypic path coefficient analysis among the different characters on flower yield per plant in various genotypes of chrysanthemum

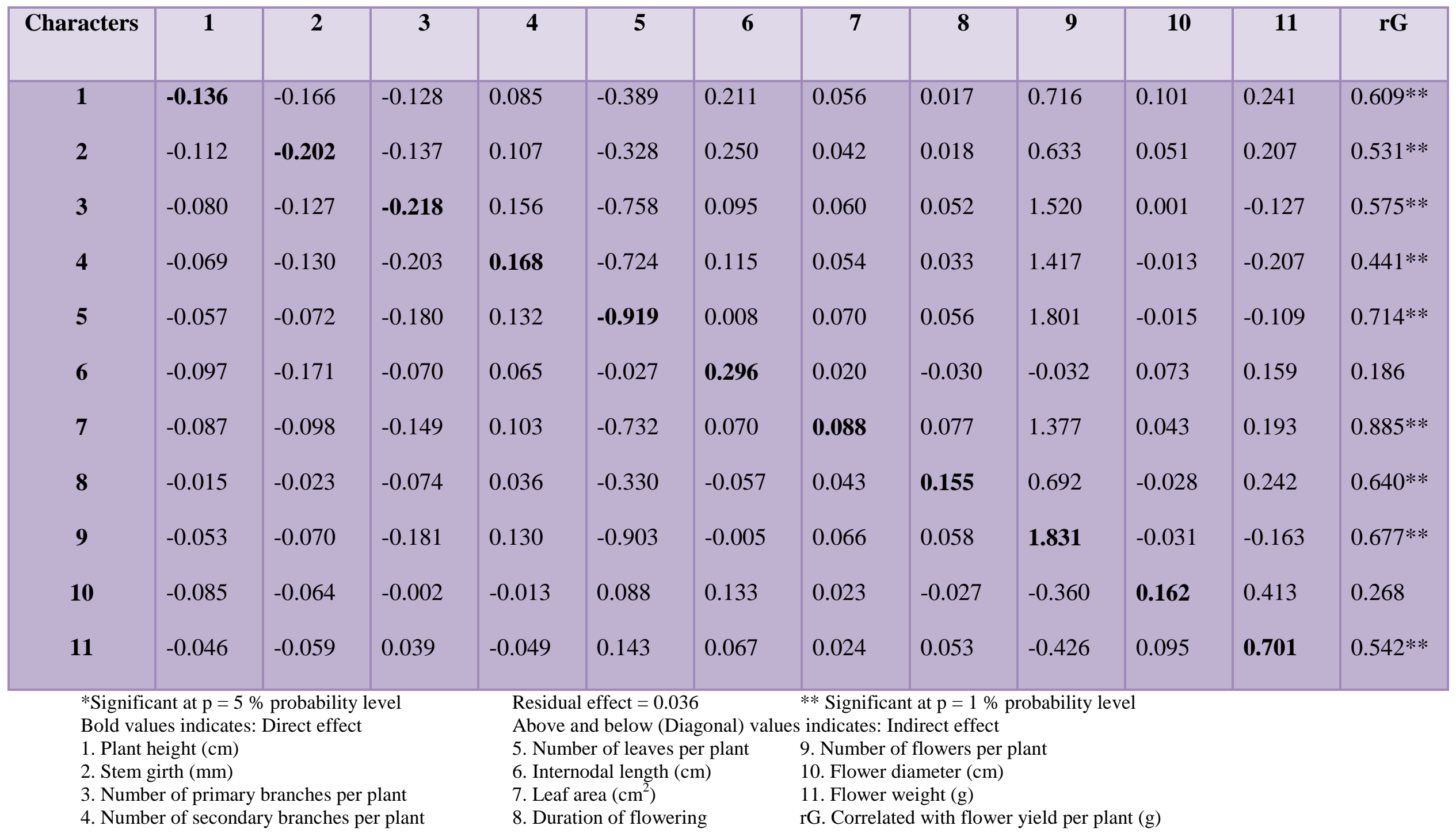


Table.4 Phenotypic path coefficient analysis among the different characters on flower yield per plant in various genotypes of chrysanthemum

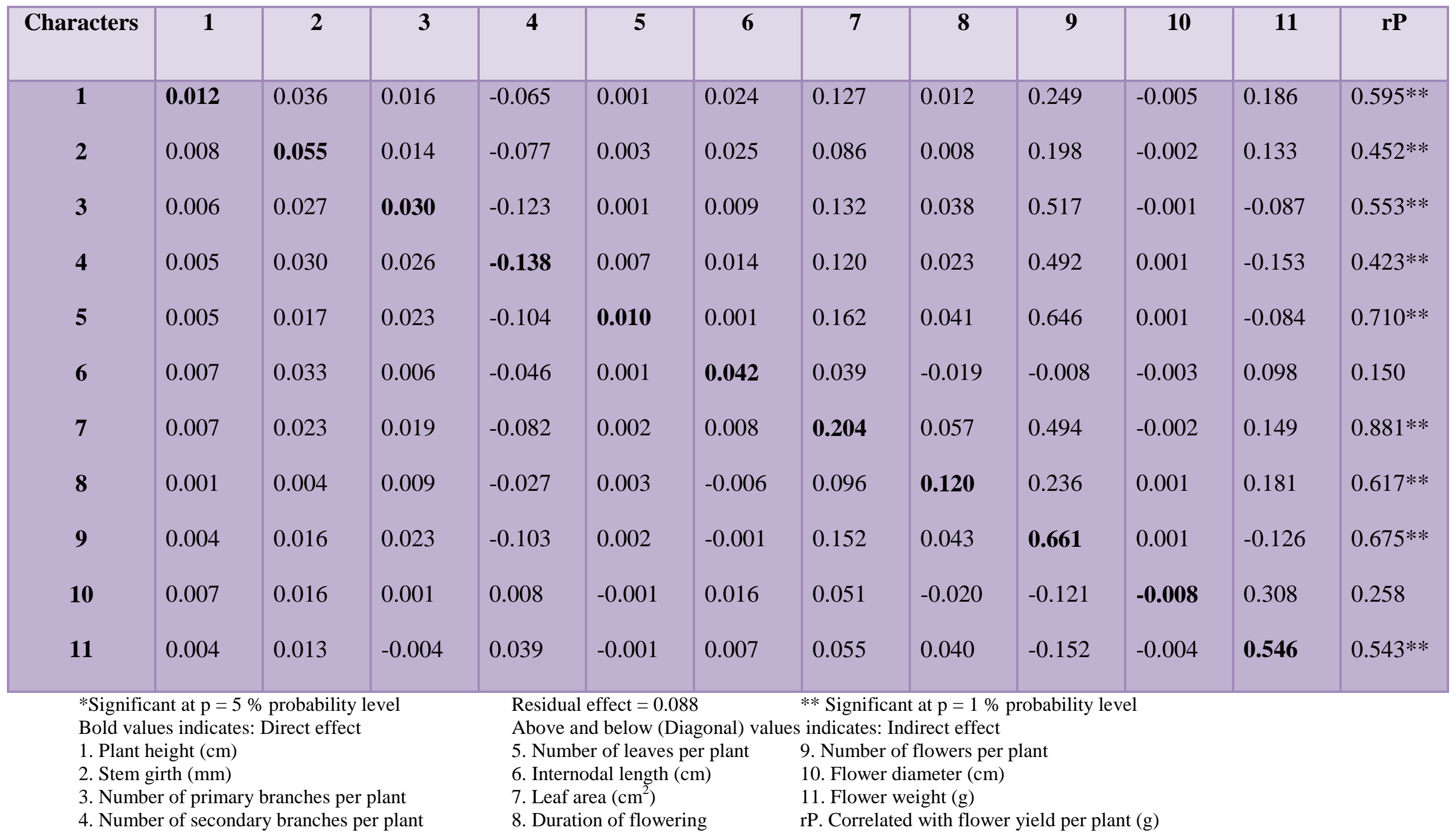


Table.1 Genotypic and phenotypic correlation coefficient among different characters in chrysanthemum

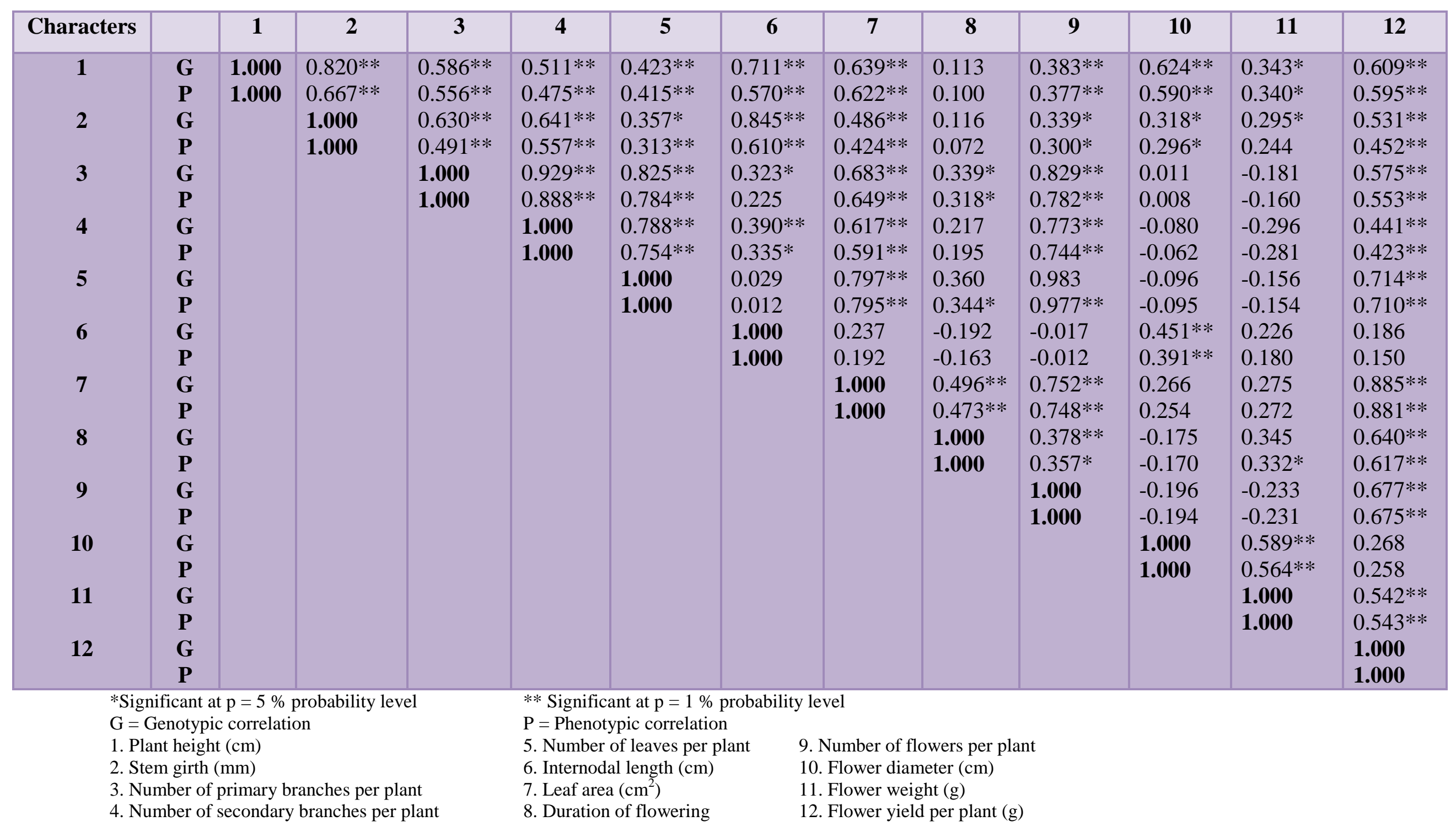


Table. 2 Genotypic and phenotypic path analysis coefficient among different characters in chrysanthemum

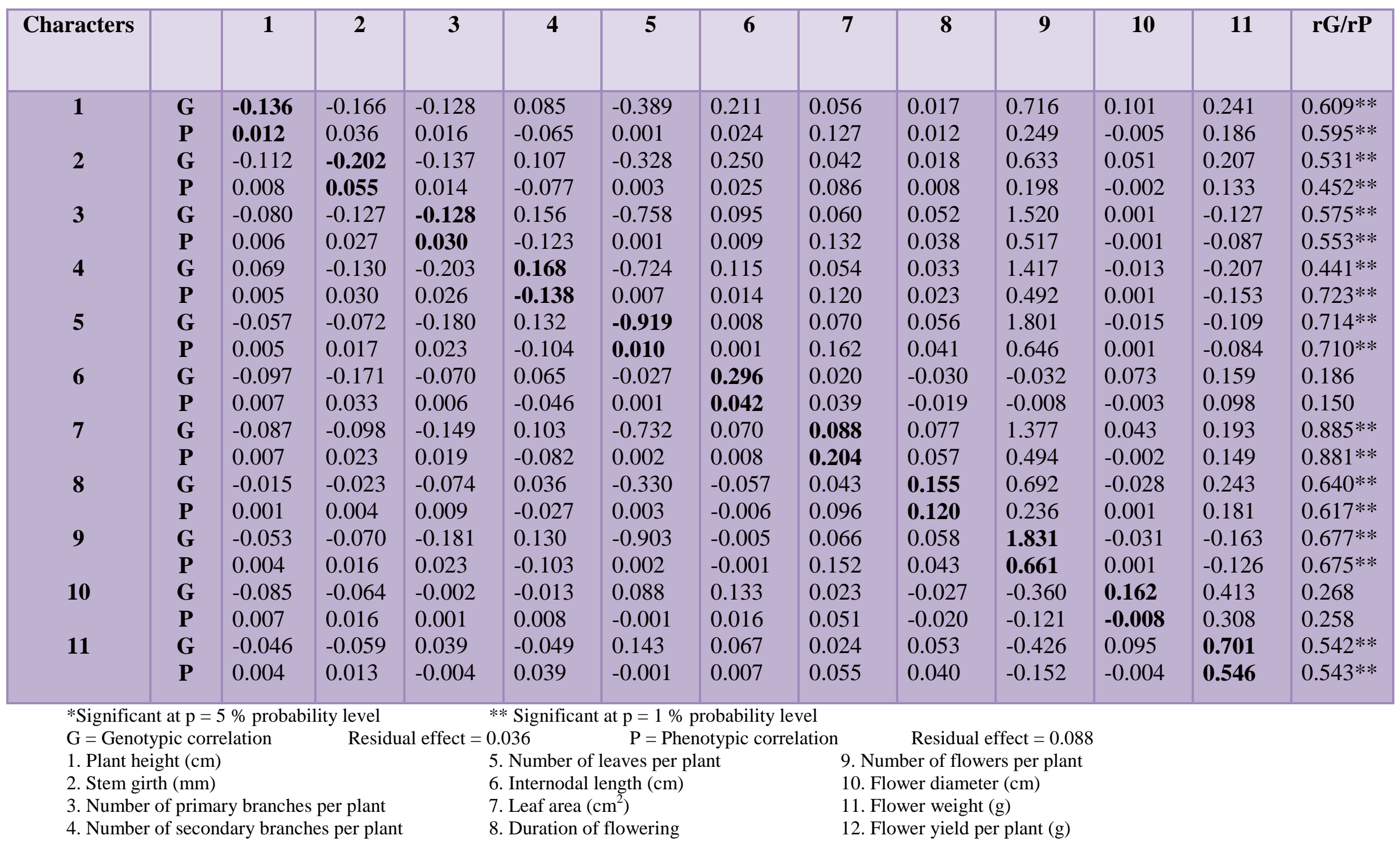


While, flower yield per plant had negatively direct effect with plant height (-0.136), stem girth (-0.202), number of primary branches per plant (-0.218), number of leaves per plant $(-0.919)$. This could be also due to the nature of certain genotypes in showing lesser regional adaptability and growth habit, resulting in a higher proportion of morphological growth than the reproductive growth leading to reduced flower yield. The results are in line with the findings of Basakran et al., (2004), Mishra et al., (2006), Mukesh et al., (2012) and Lakshmi et al., (2015) in chrysanthemum.

At the phenotypic level, number of flowers per plant (0.661), flower weight (0.546), leaf area (0.204), duration of flowering (0.120), stem girth (0.055), internodal length (0.042), number of primary branches per plant (0.030), plant height (0.012) and number of leaves per plant (0.010) exhibited maximum positively direct effect on flower yield per plant. Similar results were reported by Mukesh et al., (2012), Misra et al., (2013) and Kameswari et al., (2015) in chrysanthemum.

However, flower yield per plant had negatively direct effect from flower diameter $(-0.008)$ and number of secondary branches per plant (-0.138). However, the increased number of branches per plant after a certain limit produces more number of flowers with reduced flower size, but it limits the overall marketable flower yield. Similar results were reported by Deka and Paswan (2002) in chrysanthemum.

\section{References}

Al-Jibourie, H. A., Miller, P. A. and Robinson, H. F., 1958. Genetic and environmental variance in an upland cotton cross on inter-specific origin. Agron. J., 50: 633-637.

Baskaran, V., Janakiram, T. and Jayanthi, R.,
2004. Correlation and path coefficient analysis studies in chrysanthemum. $J$. Ornl. Hort., 7(3): 37-44.

Deka, K. K. and Paswan, L., 2002. Correlation and path analysis studies in chrysanthemum. Annal of Biology, 18(1): 31-34.

Dewey, D. R. and Lu, K. H., 1959.A correlation and path co-efficient analysis of components of crested wheat grass seed production. Agron. J., 51: 515-518.

Harland, S. L., 1939. Genetics of cotton. Jonathan Cape, London, p. 19.

Kameswari, P. L., Pratap, M., Hameedunnisabegum and Anuradha, G., 2015. Studies on genetic variability and character association for yield and its attributes in chrysanthemum (Dendranthema grandiflora Tzvelev). Agric. Sci.Digest., 35(1): 25-30.

Lakshmi, S., Balaji, K. S., Laxman, K., Patil, C. P. and Sumangala, K., 2015. Morphological and molecular characterization of chrysanthemum (Dendranthema grandiflora Tzvelev) genotypes. M. Sc. (Hort.) Thesis, Univ. Horti. Sci., Bagalkot, Karnataka.

Mishra, H. N., Das, J. N. and Palai, S. K., 2006. Genetic variability studies in spray type chrysanthemum. Orissa $J$. Hort., 34(1): 8-12.

Misra, S., Mandal, T., Vanlalruati and Das, S. K., 2013. Correlation and path coefficient analysis for yield contributing parameters in spray chrysanthemum. J. Hort. Letters, 3(1): 14-16.

Mukesh, K., Sanjay, K., Manoj, K. S., Sunil, M. and Arvind, K., 2012. Studies on correlation and path analysis in chrysanthemum (Dendranthema grandiflora Tzvelev). Int. J. Plant Res., 25(2): 62-65.

Punetha, P., RAO. V. K., Dhami, V. and Kumar, S., 2012. Correlation and path 
analysis in chrysanthemum. J. Orn. Hort., 15(3\&4): 216-221.

Prasad, Y., Kumar, K. and Mishra, S. B., 2011. Studies on genetic parameters and inter-relationships among yield and yield contributing traits in Pigeonpea [Cajanus cajan (L.) Mill sp]. The Bioscan., 8(1): 207-211.

Wright, S., 1921. Correlation and causation. J. Agri. Res., 20(7): 557-585.

\section{How to cite this article:}

Beeralingappa, P. Hemanth Kumar, Pruthvi P. Hegde and Chandrashekhar, S.Y. 2019. Correlation and Path Coefficient Analysis for Yield Contributing Parameters in Chrysanthemum (Dendranthema grandiflora Tzvelev). Int.J.Curr.Microbiol.App.Sci. 8(07): 2564-2574. doi: https://doi.org/10.20546/ijcmas.2019.807.316 